\title{
Factores de territorialización para la gestión del desastre del casco urbano de Gramalote, Norte de Santander 2010 2013 ${ }^{1}$
}

\author{
Factors of Territorialization in a Post Disaster Resettlement. \\ Gramalote - Norte de Santander 2010 2013
}

Lorena Rivera Chaves ${ }^{2}$

\section{Resumen}

A partir de la definición de territorio como constructo social, este artículo expone los seis factores de territorialización identificados durante los primeros 30 meses del reasentamiento postevento desastroso del casco urbano de Gramalote, Norte de Santander. Para ello, fueron empleadas herramientas metodológicas de tipo etnográfico, que permitieron reconocer los factores en el discurso de los involucrados, esto es, en la percepción, la representación y la toma de decisiones sobre el espacio original, los espacios transitorios y el futuro asentamiento. Esta identificación de factores de territorialización pone de relieve la necesidad de dar un enfoque espacial, que explore los aspectos cualitativos que contribuyan a mejorar la gestión de procesos de reasentamiento.

Palabras clave: desastre, percepción, reasentamiento, representación, territorialización.

\section{Abstract}

From the definition of territory as a social construct, this paper presents the six factors of territorialization identified during the first 30 month post-event disaster resettlement of the town of Gramalote, Norte de Santander. To do this, ethnographic methodological tools were employed, which allowed to recognize

1 Este artículo corresponde al proyecto "La comprensión geográfica del reasentamiento de población: factores de territorialización para la gestión del desastre del casco urbano de Gramalote, Norte de Santander". Grupo de investigación Ordenamiento Ambiental del Territorio OAT.

2 Antropóloga de la Universidad de los Andes, magister en Geografía, Programa de Estudios de Postgrado en Geografía EPG, convenio UPTC-IGAC. Colombia. Iorena.rivera.chaves@gmail.com 
the factors in the speech of the ones involved, i.e., perception, representation and decision making on the original space, transitional spaces and the future settlement. This identification of territorialization factors highlights the need for a spatial approach that explores the qualitative aspects that contribute to improving the management of resettlement processes.

Keywords: disaster, perception, resettlement, representation, territorialization. 


\section{Introducción}

\section{El reasentamiento como proceso de territorialización}

Los modelos de comprensión que orientan la ejecución de reasentamientos de población después de un evento desastroso, han privilegiado una perspectiva temporal que reduce lo espacial a la consecución de un refugio o vivienda según la etapa de la reubicación en la que se encuentre la población afectada. La necesidad de incorporar una perspectiva geográfica a estos modelos de comprensión, en la que a partir de la percepción y de la representación del territorio de los actores involucrados se identifiquen recomendaciones para la gestión del reasentamiento, se encuentra en el centro de esta investigación, que busca dar nuevas respuestas a las realidades actuales de ocurrencia de desastres y del reasentamiento como estrategia de recuperación.

Un desastre se define como un daño severo y una ruptura de las funciones esenciales de una población, lo cual implica una pérdida humana, material y ambiental, que supera la capacidad de la comunidad de sobrellevar la situación sin ayuda externa (Quarantelli, 1998). El reasentamiento es comprendido como un proceso que conduce a la recuperación del desastre, teniendo en cuenta que el espacio en el que ocurrió el evento se encuentra en alto riesgo no mitigable y que ante la probabilidad de que el fenómeno vuelva a ocurrir, se hace necesario construir un nuevo asentamiento considerado como seguro.

Scudder y Colson (1982) han definido un modelo explicativo de los reasentamientos que ha sido referencia en las investigaciones y en la ejecución de este tipo de procesos, el cual consta de cuatro momentos, la etapa de reclutamiento en la que se identifica la población por reubicar, la de transición, que inicia con el desalojo y termina con la adaptación al nuevo ambiente, la de desarrollo potencial, en la que las personas han establecido suficientemente sus sistemas de producción, y la de incorporación, en la que la comunidad ha establecido relaciones normalizadas con el gobierno, con otras comunidades y con el mundo exterior. Aproximaciones más recientes financiadas por el Banco Mundial, han retomado este modelo para orientar a los hacedores de política cuando es necesario llevar a cabo un reasentamiento.

Estas aproximaciones en las que se combinan elementos de la investigación con las políticas de entidades financiadoras, conducen a Oliver Smith (2001) a afirmar la existencia de tres aspectos que no necesariamente contemplan estos modelos:

a) la responsabilidad de la sociedad frente a las condiciones de vulnera- 
bilidad de las poblaciones reasentadas, b) la evaluación y la percepción del riesgo diferenciada entre los expertos y la población, y c) los impactos negativos del reasentamiento. Adicionalmente puede reconocerse la ausencia de una perspectiva espacial, pues al enfocarse en la temporalidad y reducir el espacio al refugio o vivienda, se asume que al trasladarse de un predio a otro la población deja de relacionarse con los asentamientos en los que ocurrió el desastre o en los que habitó transitoriamente, sin contemplar las relaciones emocionales y funcionales con estos territorios.

Indagando frente a este último aspecto, la investigación, cuyos primeros resultados presenta este artículo, ha tenido como objetivo general, comprender el reasentamiento de población desde una perspectiva geográfica a través de la definición de factores cualitativos de territorialización, que conduzcan a la identificación de recomendaciones para mejorar la gestión territorial de reubicaciones de cascos urbanos como el del municipio de Gramalote, Norte de Santander. Lo anterior, a partir de la hipótesis según la cual, la comprensión del reasentamiento de población como una sucesión de etapas que concluyen con la entrega de una vivienda a la población afectada, no da cuenta de la complejidad de un proceso geográfico que podría llegar a mejorarse a través de una adecuada gestión territorial. En ese sentido, el artículo expone los seis factores de territorialización identificados durante los primeros treinta meses desde que ocurrió el evento desastroso en Gramalote, Norte de Santander.

Este objetivo parte en lo teórico y en lo metodológico desde el constructivismo geográfico, según el cual, una realidad espacial puede ser conocida por medio de categorías previas que configuran la actuación e interacción de los seres humanos (Orain, 2007). La concepción de un espacio construido socialmente ${ }^{3}$ ha implicado hacer una lectura de las prácticas, para definir el territorio como "un conjunto de representaciones, las cuales van a desembocar, pragmáticamente, en una serie de comportamientos, inversiones, tiempos y espacios sociales, culturales, estéticos, cognitivos" (Guattari \& Rolnik, 2006, p. 323).

La definición de seis factores que explican la manera en la que simultáneamente se territorializan los

3 La concepción de construcción social del espacio se diferencia de la de producción social del espacio en que esta última, "ha privilegiado abordajes desde afuera de lo observado, esto es, desde el punto de vista de un observador externo porque el espacio producido es reconocido como una huella, una marca o impronta que queda y puede ser reconocida por un observador externo" (Lindon, 2008, p. 9). Por su parte, el constructivismo se pregunta por el sujeto, no sólo en su condición de elemento tangible sino en la forma como representa su realidad geográfica (Lindon, 2008). 
espacios original, transitorios ${ }^{4} \mathrm{y}$ el futuro asentamiento en su relación con la forma en la que los individuos perciben el lugar, las comunidades representan sus espacios de vida y la sociedad en general toma decisiones de agenciamiento, llevan a la necesidad de abordarlo en la gestión municipal, departamental y nacional con una perspectiva espacial. Al igual que en Gramalote, otros municipios se enfrentan o se enfrentarán a reubicaciones derivadas de la ocurrencia de un evento desastroso, por tanto, resulta de gran relevancia la posibilidad de contribuir a la comprensión de esta problemática. Esta investigación se constituye en un aporte a la discusión acerca de la territorialización y la gestión espacial en un reasentamiento poblacional involuntario.

\section{Metodología para la identifica- ción de factores cualitativos de territorialización}

En diciembre de 2010, el casco urbano de Gramalote, Norte de Santander, fue destruido a raíz de un movimiento en masa, resultado de un aumento en la intensidad de las lluvias durante el período de ola in-

4 Los espacios transitorios comprendidos como aquellos en los que se ubica la población mientras ocurre la construcción de las viviendas y equipamientos definitivos. En la experiencia de Gramalote, la población ha permanecido durante treinta meses en los espacios transitorios, sin que haya iniciado aún la construcción física del nuevo casco urbano. vernal. Los habitantes evacuaron de emergencia ante la destrucción de las viviendas, los equipamientos y el espacio público, y las autoridades confirmaron la imposibilidad de su retorno al considerarse como una zona de alto riesgo no mitigable.

Desde el evento desastroso, la población se ha ubicado de manera temporal en albergues o como arrendatarios en otros municipios del departamento de Norte de Santander, así como en la zona rural de Gramalote y en algunos casos, retornando al casco urbano en el que ocurrió el desastre. El proceso ha sido liderado por el Gobierno nacional en medio de una situación de inestabilidad política en la escala local, con presencia de múltiples actores y en el marco de un proceso cambiante de definición del futuro asentamiento que ha presentado demoras y que ha dividido a la comunidad entre las dos opciones de reubicación en la zona El Pomarroso y en los alrededores del Instituto Agrícola en la vereda Miraflores 5 .

La información para esta investigación fue obtenida a partir de obser-

5 Los estudios de prefactibilidad del reasentamiento, realizado durante el año 2011, presentaron como opción más viable y adecuada la zona El Pomarroso, decisión que fue ratificada por las entidades responsables en el Gobierno nacional, y dio inicio a los trámites legales para la compra de los predios. No obstante, durante el año 2012 y después de varios meses de estancamiento del proceso, el Gobierno nacional anunció que el reasentamiento se realizaría en la vereda Miraflores. 


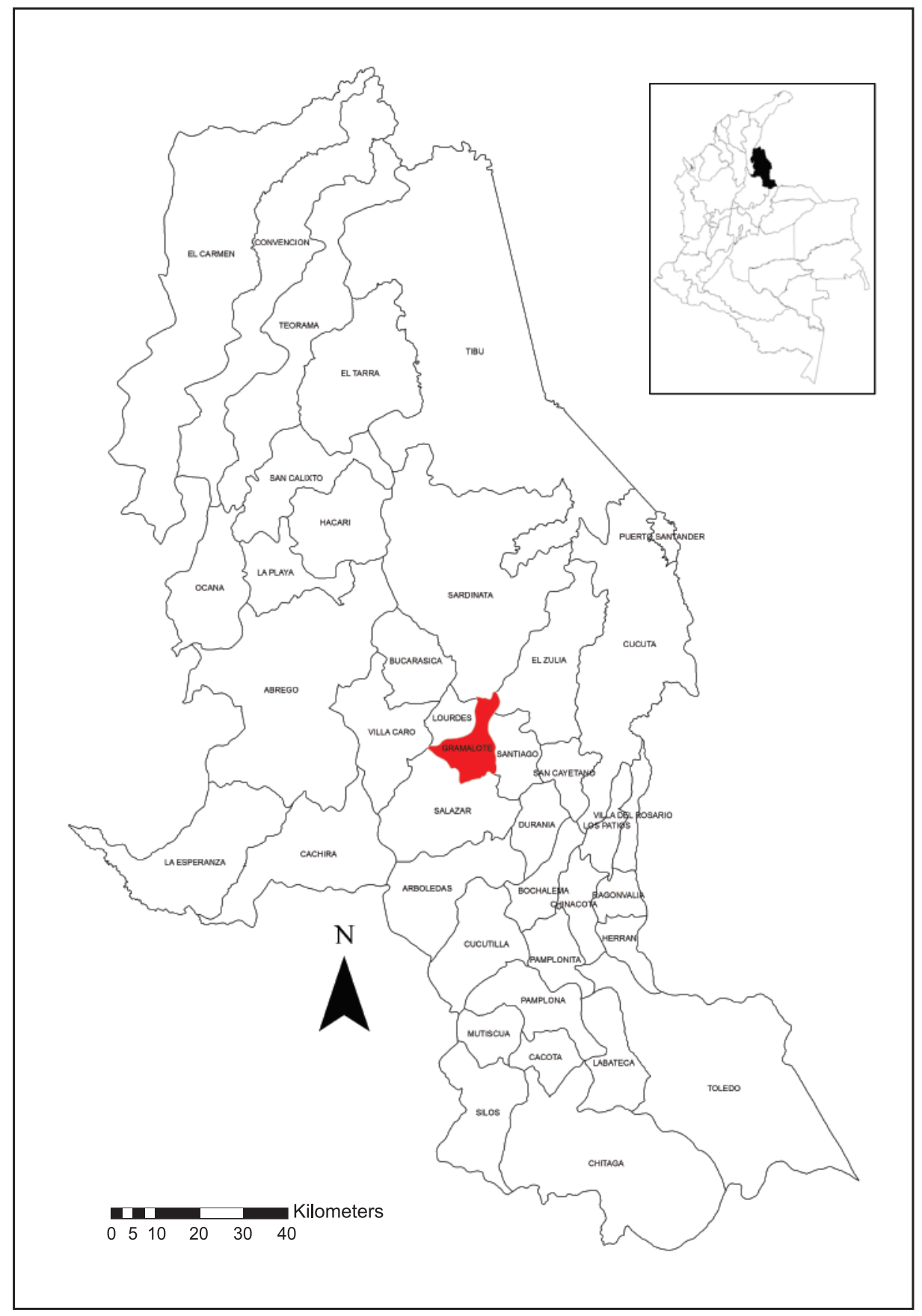

Figura 1. Localización de Gramalote en el departamento de Norte de Santander.

Fuente: elaboración propia a partir de datos del Instituto Geográfico Agustín Codazzi (2010). 
vación participante y de entrevistas semiestructuradas en escenarios relacionados con el reasentamiento ${ }^{6}$, adicionalmente se hizo un seguimiento de las redes sociales, prensa nacional y regional y una consulta permanente a los documentos de las entidades involucradas. La observación permitió identificar actores-informantes de la comunidad, así como funcionarios locales que fueron entrevistados.

El tratamiento de la información se hizo mediante un análisis comprensivo del discurso, en el cual se busca identificar las principales categorías en los relatos y clasificar la información según esta identificación (Kornblit, 2007). Mediante la herramienta de análisis cualitativo Atlas Ti 6.0, este proceso permitió reconocer seis etiquetas (codes) principales correspondientes a los factores de territorialización más recurrentes que se presentan en la Figura 2, y tres etiquetas dependiendo de si las citas (quotes) presentaban una percepción, una representación o una decisión de los involucrados. En el siguiente capítulo se describe cada uno de estos factores, y se explican los principales hallazgos a partir del análisis comprensivo realizado.

6 La observación participante se realizó en once escenarios durante los años 2011 y 2013, en los que ha participado la administración municipal, la administración departamental, las entidades encargadas del Gobierno nacional, la comunidad en general, los contratistas del proceso y otros actores externos como agremiaciones y organizaciones no gubernamentales.

\section{Los factores de territorializa- ción en los espacios del reasen- tamiento del casco urbano de Gramalote, Norte de Santander}

Un factor se define como una concausa, como un elemento o variable que en conjunto con otros aspectos conduce a la territorialización de los espacios del reasentamiento. A continuación se presentan los seis factores identificados como categorías dobles entre las que se territorializa de manera simultánea el espacio en el que ocurrió el evento desastroso, los espacios transitorios y el futuro asentamiento en el que se espera se ubique la población al finalizar la reubicación.

\subsection{Primer factor de territorializa- ción: dispersión y hacinamiento}

Una vez ratificada la imposibilidad de volver a habitar el casco urbano original, las familias gramaloteras buscaron de manera autónoma nuevos lugares para vivir, mientras esperan la construcción del nuevo asentamiento. El primer factor hace referencia a la localización dispersa de los gramaloteros durante la reubicación y a cómo, de manera simultánea, la experiencia espacial se ha visto afectada por problemas de hacinamiento en el lugar de vivienda.

En Gramalote se han hecho diferentes censos que arrojan información 


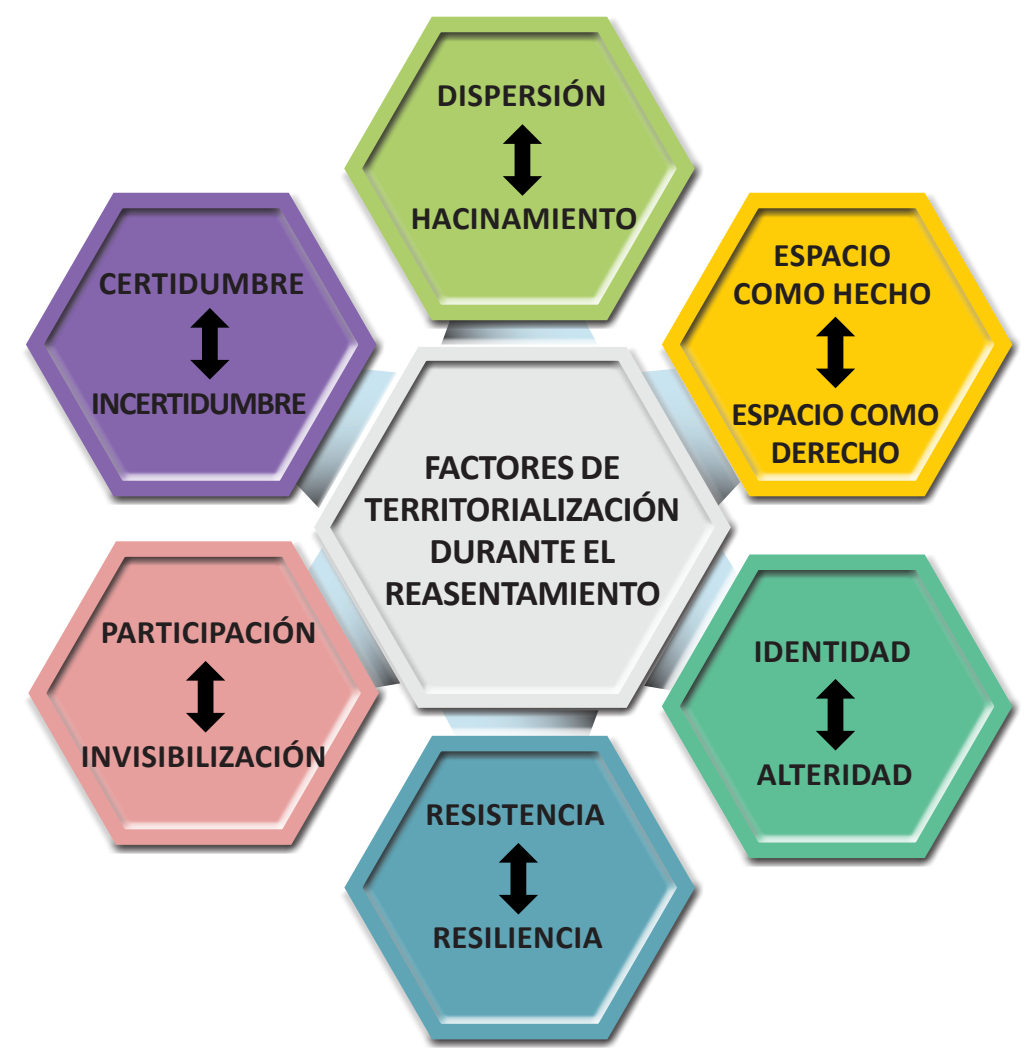

Figura 2. Factores de la territorialización identificados en el discurso de los actores.

Fuente: elaboración propia

sobre la dispersión de la población. El censo realizado para el Plan de Desarrollo Municipal 2012-2015, identificó 1.244 hogares, de los cuales diez se ubican fuera de Norte de Santander. De los hogares ubicados dentro del departamento, el 60,43\% se encuentra en la capital, el 6,5\% en la zona rural de Gramalote y el restante $33,07 \%$ en otros 18 municipios. Por su parte, el censo efectuado por la Fundación Servicio de Vivienda Popular Servivienda (2012), que realizó el estudio de prefactibi- lidad del reasentamiento, tuvo como resultado 124 hogares menos que el Plan de Desarrollo, distribuidos en 16 municipios y sin señalar la existencia de familias fuera del departamento. En la Figura 3 se comparan los resultados de estos dos censos, en azul la dispersión y número de hogares gramaloteros en cada municipio según el Plan de Desarrollo, y con cuadrículas el censo de Servivienda.

Las particularidades conceptuales y metodológicas de cada uno de los 
censos, así como la alta movilidad de la población que no logra adaptarse en sus espacios transitorios, pueden llegar a explicar las diferencias entre los datos representados en el mapa de la Figura 3, donde se evidencia un menor número de familias por municipio según Servivienda. Desde otra lectura, las diferencias entre estos censos, también denotan las dificultades de las autoridades en la identificación de la línea base, haciendo que la dispersión se constituya en un impedimento para el acceso a la institucionalidad y al reconocimiento de los derechos de los afectados.

De manera simultánea a la dispersión, las familias se enfrentan a condiciones de hacinamiento. Un gramalotero entrevistado afirma que si bien extraña a sus vecinos y amigos que se encuentran en diferentes municipios, en la vivienda en la que reside en Cúcuta se encuentra viviendo en una sola casa con otras 17 familias gramaloteras, lo cual ha traído problemas de convivencia y de distribución de las ayudas recibidas (comunicación personal, 10 de abril de 2011).

Para los afectados, la dispersión es percibida como el verdadero desastre más allá de la destrucción física del casco urbano, mientras que el hacinamiento es entendido como una situación problemática que ante los pocos ingresos familiares no tiene una solución a corto plazo. En cuan- to a los albergues de organizaciones privadas, si bien la población percibe las dificultades por las dimensiones de la unidad familiar que tiene un área aproximada de $22 \mathrm{~m}^{2}$, señalan que estos se constituyen en puntos de encuentro y en centros de la vida social ante la dispersión de su comunidad.

Ante estas problemáticas y la ausencia de respuestas inmediatas, las entidades gubernamentales del orden nacional anuncian el futuro casco urbano como un centro de reencuentro y de recuperación de las relaciones perdidas, así como un nodo regional y turístico, situación que se percibe como lejana para la comunidad dadas las dificultades para definir el terreno, así como el atraso en el inicio de obras viales que permitan la conectividad con la zona rural y con otros municipios. Para la población, la consolidación como un centro turístico resulta del desconocimiento del Gobierno nacional sobre las capacidades e intereses de la comunidad y de la relación histórica que los gramaloteros han tenido con su territorio.

En este factor de dispersión y hacinamiento cabe señalar que el agenciamiento sobre el espacio, responde más a decisiones autónomas de los individuos que a una planificación de las autoridades; la falta de certeza sobre la ubicación de los afectados y 
los problemas de hacinamiento, han derivado en procesos de construcción de territorio mediados por el segundo factor de territorialización que alude a una permanente incertidumbre sobre los espacios habitados.

\subsection{Segundo factor de territoriali- zación: certidumbre e incerti- dumbre}

La certeza sobre la posibilidad de habitar un territorio o la ausencia de esta, ha sido un factor permanente después de ocurrido el evento desastroso. Como pudo evidenciarse en el factor anterior, no existe claridad sobre la ubicación de los afectados en el territorio transitorio, así como tampoco hay certeza sobre el número de hijos de gramaloteros nacidos después del evento, ni sobre las nuevas familias conformadas y su derecho a participar en el reasentamiento.

Por otra parte, la ubicación del futuro casco urbano se ha modificado, estableciéndose oficialmente en el sitio conocido como El Pomarroso y posteriormente en el sitio del Instituto Agrícola en la vereda Miraflores que se representan en la Figura 4. Las permanentes disputas entre sectores de la comunidad por la preferencia de una u otra ubicación, así como de grupos políticos y de múltiples intereses en cada una de estas zonas, se han constituido en una de las causas de mayor incertidumbre. Un gramalotero que actualmente se encuentra en Cúcuta señala que la disputa tiene relación con la propiedad de una reserva hídrica que se vería afectada por la construcción del casco urbano (comunicación personal, 23 de abril de 2013). Al superponer los usos del suelo del Esquema de Ordenamiento Territorial del municipio del año 2002, con las opciones para el reasentamiento como se presenta en la Figura 4 , es posible identificar que los predios de la zona del Instituto Agrícola en la vereda Miraflores, se encuentra sobre la reserva ecológica El Bojoso. Esta situación ha desatado discusiones entre la comunidad, amenazas contra la vida y la seguridad de algunos líderes así como la deserción del proceso de representantes de la comunidad ante el Gobierno nacional.

La inseguridad sobre el espacio que espera ser habitado, ha implicado en lo individual problemas psicológicos y psiquiátricos, y en lo social, la falta de credibilidad de los actores institucionales, lo que ha motivado a algunas familias a establecerse de manera definitiva y autónoma en zonas de riesgo, en la periferia urbana de Cúcuta, en la vía que de esta ciudad conduce a Gramalote y en el destruido casco urbano. 


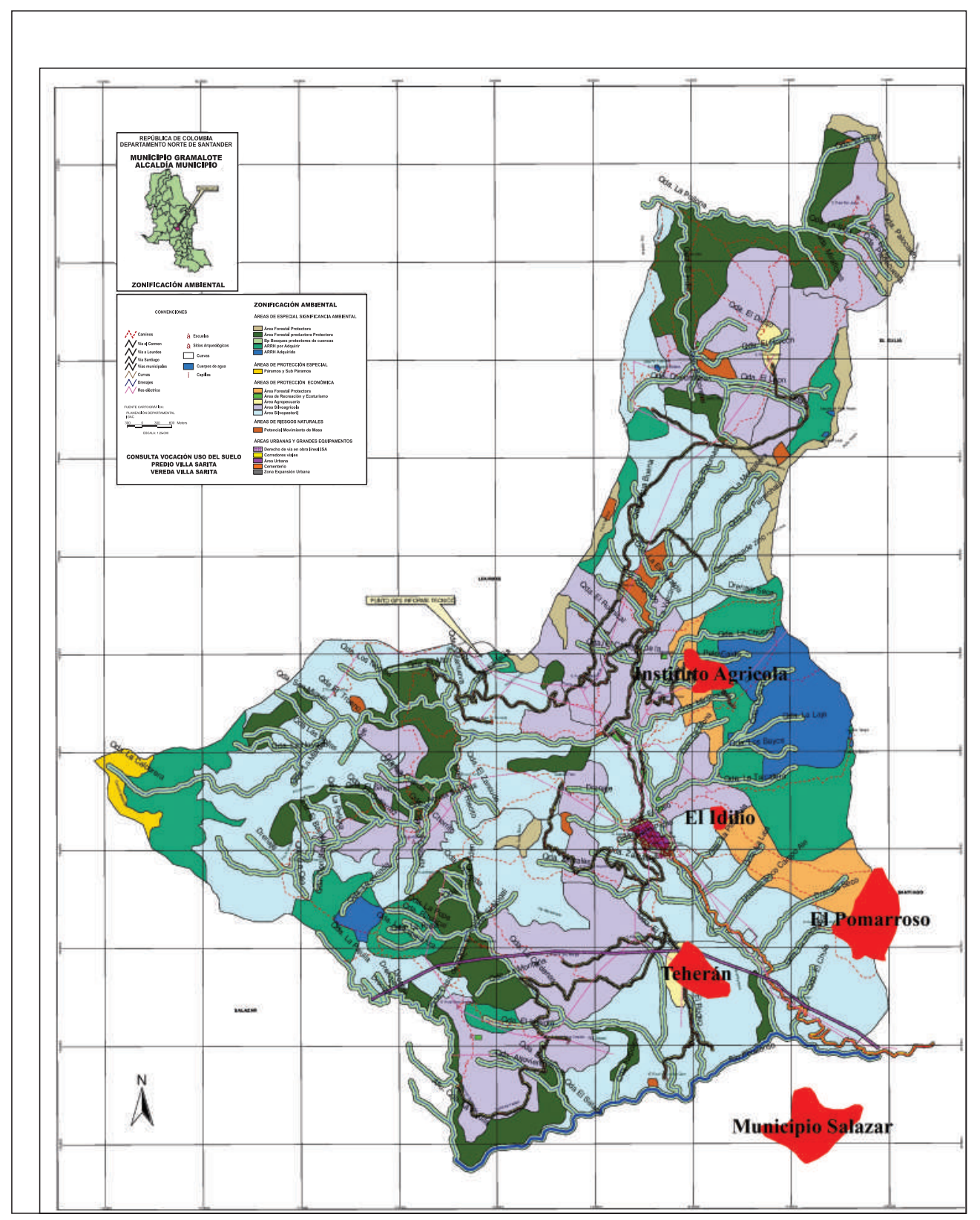

Figura 4. Ubicación de las zonas para el reasentamiento y zonificación según EOT.

Fuente: Municipio de Gramalote (2012). 


\subsection{Tercer factor de territorializa- ción: identidad y alteridad}

La imposibilidad de habitar el casco urbano original, ha conducido a los pobladores a enfrentarse a sus sentimientos de identidad territorial y a su encuentro con los otros. El problema de la identidad y de la alteridad, interesa a la geografía en la forma como los seres humanos se delimitan a sí mismos y ello se traduce en prácticas socio espaciales, "Geographers have drawn upon these ideas to show how the Self is a cultural production that relies on socio spatial practices of inclusión and exclusión"7 (Gregory et al., 2009, p.534) A su vez, la otredad es considerada como lo que se encuentra fuera de sí mismo y ello marca límites en las relaciones espaciales.

La exacerbación de los sentimientos de pertenencia se ha reflejado a través de manifestaciones artísticas y culturales, así como de los mensajes que los pobladores trasmiten en sus diferentes formas de expresión. Es evidente en el discurso de los pobladores, el arraigo y los sentimientos de pertenencia por el espacio perdido, lo cual se profundiza por el rechazo de quienes son originarios de los espacios transitorios.

7 Los geógrafos han recurrido a estas ideas (conceptos de alteridad y otredad), mostrando cómo la individualidad o el "sí mismo" es una producción cultural basada en prácticas socioespaciales de inclusión y exclusión.
Según un líder comunitario, las personas que han permanecido en otros municipios han sido rechazadas por los locales (com. pers., 1 abril 2012). Por su parte, el coordinador del Centro Regulador de Urgencias afirma que los niños, niñas y adolescentes han sido víctimas de bullying en los colegios en los que comparten con los menores de los espacios transitorios (Revista Semana, 2011), lo cual ha motivado la deserción escolar y la estigmatización de los gramaloteros en edad escolar. Quienes manifiestan haber sido bien recibidos, afirman de igual forma la sensación de sentirse extraños y ajenos a la dinámica de otros territorios.

Esta doble condición de extrañeza frente a los espacios transitorios y de añorar el espacio original, ha sido una de las motivaciones de un fenómeno de retorno a algunos barrios del destruido casco urbano,

Durante este semestre, diez familias han decidido volver a su pueblo y vivir en él (...), se han ubicado en La Lomita que se ha convertido en el sitio de encuentro y centro de acopio, pues tiene cinco tiendas, dos peluquerías y ventas de minutos a celular. Los domingos se volvieron los días más especiales para sus habitantes porque el padre (...) baja de la vereda Boyacá y celebra misa en un improvisado templo (Sánchez, 2011). 


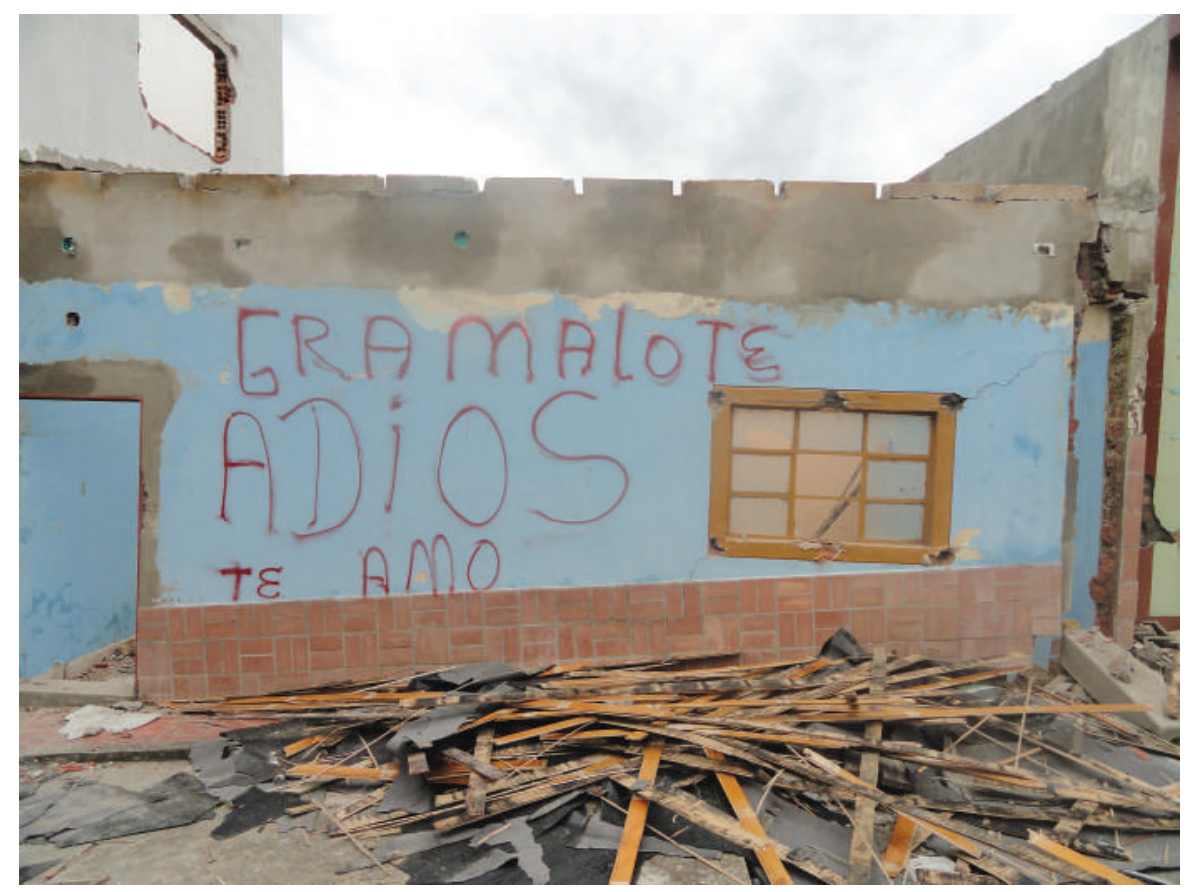

Figura 5. Mensajes durante la evacuación del municipio en el año 2010.

Fuente: elaboración propia.

Esta situación se ha ampliado a otros barrios en donde es posible encontrar viviendas que no se han destruido completamente y en las que la población prefiere ubicarse mientras esperan la reconstrucción del asentamiento, pues a pesar de las condiciones de alto riesgo, se encuentran en un territorio que sienten como propio.

\subsection{Cuarto factor de territorializa- ción: resistencia y resiliencia}

Las investigaciones sobre riesgos y desastres han involucrado los conceptos de resistencia y resiliencia como elementos de la vulnerabili- dad, entendida no sólo como desencadenante de un desastre en conjunto con una amenaza, sino como un efecto del evento desastroso que se prolonga y se transforma años después durante la recuperación de una comunidad. La resistencia hace referencia a la inflexibilidad a aceptar los cambios que representa un desastre, mientras que la resiliencia hace alusión a la adaptación para la recuperación y el restablecimiento de los medios de vida (Chardon \& Suárez, 2010).

La resistencia y la resiliencia son aspectos que se combinan en la vida cotidiana de los damnificados y que 
evidencian condiciones de vulnerabilidad que dificultan el reasentamiento y la toma de decisiones sobre el territorio. La población se encuentra empobrecida, desanimada, con dificultades para acceder a programas de atención, servicios básicos y oportunidades económicas, así como vulnerabilidad en adultos mayores y niños, quienes no han logrado adaptarse a la nueva realidad y han sufrido la desarticulación de su núcleo familiar y de su comunidad (Servivienda, 2012).

A pesar de ello y de los conflictos identitarios, parte de la población, particularmente los jóvenes residentes en Cúcuta, han empezado a adaptarse a la vida urbana, con la posibilidad de acceder a educación superior, a empleo y a una oferta cultural amplia, lo cual cuestiona a los gramaloteros sobre la intención real de una parte de la población de reubicarse cuando se construya el casco urbano, que según los cronogramas tardará tres años más. En el lapso de la temporalidad las familias se habrán insertado en la dinámica de sus espacios transitorios y su traslado al nuevo casco urbano podría ser inviable.

\subsection{Quinto factor de territoriali- zación: espacio como hecho y espacio como derecho}

El quinto factor de territorialización se relaciona con la tenencia de la tie- rra que se expresa como una dualidad entre el derecho que reclaman los afectados a tener un espacio digno durante la transitoriedad y su expectativa de trasladarse al futuro casco urbano, y las situaciones de hecho que los han llevado a ocupar predios en zonas de alto riesgo o sobre los que no tienen ninguna propiedad.

Un elemento que ha sido invisibilizado en el discurso sobre el reasentamiento de Gramalote, es el del derecho de las familias a trasladarse al futuro casco urbano. Según el Esquema de Ordenamiento Territorial, solo el $52 \%$ de la población urbana era propietaria de la vivienda antes del desastre, mientras que el $29 \%$ se encontraba en arriendo y el $19 \%$ tenía otras formas de tenencia, subarrendatarios y poseedores sin títulos (municipio de Gramalote, 2002). Un líder comunitario menciona que los gramaloteros no han dimensionado la gravedad de la situación frente a la propiedad y que las instituciones tampoco se han preocupado por dar esa discusión,

Ya se tenía que haber hecho el saneamiento de títulos porque eso va a retrasar la reubicación, mientras tanto todos los gramaloteros piensan que van a inaugurar el nuevo pueblo y que todos van a tener casa y no se han preguntado si esto es así o no. (Com. pers., 23 de abril 2013). 
En cuanto al territorio transitorio y como se mencionó en los factores de certidumbre e incertidumbre y de identidad y alteridad, la población ha tomado vías de hecho, habitando zonas de alto riesgo como resistencia a las alternativas establecidas de albergues o arrendamiento y como realización de su derecho a tener un lugar de vivienda.

\subsection{Sexto factor de territorializa- ción: participación e invisibili- zación}

Las investigaciones sobre reasentamiento de población ponen de manifiesto la importancia de la participación comunitaria desde la valoración de los daños, hasta las decisiones de selección del terreno y diseño, así como la necesidad de contar con un gobierno con la capacidad para facilitar esta participación y lograr que a través de esta se puedan identificar problemas, establecer necesidades, hacer un proceso sostenible y mejorar la eficiencia de los recursos locales (Méheux, Dominey \& Lloyd, 2010). En este factor, se identifica en el caso de Gramalote que la territorialización del espacio transitorio es llevada a la realidad por una comunidad que toma decisiones y se apropia de dichos espacios de manera independiente e incluso contradictoria con el proceso oficial de reasentamiento, y que a la vez es invisibilizada por otros tomadores de decisiones.
La participación de los gramaloteros después del evento desastroso se percibe y se representa en el discurso como reducida. Los escenarios de encuentro de las entidades con la comunidad, han funcionado con la lógica de socializar resultados, sin que ello se constituya en un ámbito de participación o diálogo, tratándose de informar y de responder preguntas sobre las decisiones ya tomadas, lo cual está acompañado según los gramaloteros, de un lenguaje técnico que para ellos es incomprensible (com. pers., 25 de abril de 2013).

Además de la invisibilización de la comunidad, las instancias democráticas del ámbito local como la alcaldía y el concejo municipal, son representadas en el discurso de las entidades nacionales encargadas del proceso como ámbitos con poca capacidad para la participación y la toma de decisiones sobre el territorio. A pesar de la representatividad de la autoridad municipal, el Decreto Nacional 1159 de 2011 creó una comisión intersectorial para el proceso Gramalote,

El presidente de la comisión intersectorial podrá invitar a las reuniones a funcionarios y representantes de entidades públicas o privadas del orden nacional, departamental o municipal que estime necesarias, quienes tendrán la facultad de asistir a las sesiones con derecho a voz. 
Podrá invitar al Gobernador y al Alcalde quienes tendrán la facultad de asistir a las sesiones con derecho a voz (MAVDT, 2011).

El decreto no reconoce a las autoridades locales y regionales como parte de la comisión y en caso de ser invitados, no les otorga voto en las decisiones. Por otra parte, cabe mencionar que la participación ha sido reducida a la división entre quienes favorecen Pomarroso y quienes favorecen la zona del Instituto Agrícola en Miraflores como opciones para la reubicación, mientras que otros aspectos como el futuro del área afectada por el desastre, la solución a las problemáticas en los territorios transitorios, los problemas con el acceso a educación y empleo, el derecho al territorio, han quedado excluidos del diálogo con los gramaloteros.

\section{Conclusiones}

El objetivo de explicar la territorialización durante el reasentamiento del casco urbano de Gramalote, ha permitido incorporar una perspectiva espacial que trasciende los modelos de explicación en los que el espacio es reducido al refugio o lugar de vivienda. De esta forma, ha sido posible afirmar la hipótesis según la cual, la comprensión del reasenta- miento como una sucesión de etapas no permite comprender la complejidad del proceso, siendo la reubicación un proceso de construcción social de los espacios que involucra simultáneamente, el espacio original, los transitorios y el futuro casco urbano.

La aproximación metodológica de tipo etnográfico, pone de relieve la pertinencia de incluir modelos de la experiencia humana, como una de las responsabilidades de los profesionales para iniciar una geografía de la acción (Di Méo, 2008). En ese sentido, el diálogo con los involucrados y la posibilidad de investigar sobre las percepciones y representaciones, ha permitido abordar otro tipo de factores no contemplados en las investigaciones sobre reasentamientos.

Estos seis factores identificados evidencian la complejidad y ambigüedad de una reubicación dada la multiplicidad de espacios, actores e intereses, y arrojan puntos críticos sobre la ejecución de un proceso de este tipo. Ello supone la necesidad de continuar explorando los factores cualitativos de territorialización con el objetivo de describirlos pero, adicionalmente, con el propósito de construir recomendaciones para la gestión, en las que se contemple la participación significativa de los involucrados en la construcción social de los espacios del reasentamiento. 


\section{Referencias}

Chardon, A. K. \& Suárez, J. F. (2010). Reasentar más allá de cuatro muros. Un análisis de la teoría y la praxis del hábitat sostenible. Bitácora, 16, 11 - 34 .

Di Méo, G. (2008). Geografía social entre las representaciones y la acción. Montagnes méditerranéennes et développement territorial, 23, 13 - 21.

Fundación Servicio de Vivienda Popular-SERVIVIENDA- (2012). Estudios de prefactibilidad. Lineamientos y recomendaciones para el reasentamiento del casco urbano del municipio de Gramalote. Bogotá: SERVIVIENDA.

Gobierno admite debilidad en atención psicosocial a víctimas de invierno (2011, 1 de abril). Revista Semana. Recuperado de: http://www.semana.com/nacion/articulo/gobiernoadmite-debilidad-atencion-psicosocial-victimas-invierno/237771-3

Gregory, D., Johnston, R., Pratt, G., Watts, M. J. \& Whatmore, S. (2009). The Dictionary of Human Geography. Oxford: Blackwell

Guattari, F. \& Rolnik, S. (2006). Micropolítica. Cartografias del deseo. Madrid: Traficantes de Sueños.

Kornblit, A. L. (2007). Historias y relatos de vida: una herramienta clave en metodologías cualitativas. En A. L. Kornblit. (Coord). Metodologías cualitativas en ciencias sociales: Modelos y procedimientos de análisis (pp. 22 - 33). Buenos Aires: Biblos.

Lindón, A. (2008). De las geografías constructivistas a las narrativas espaciales como metodologías geográficas cualitativas. Revista da ANPEGE, 4, 3-27.

Méheux, K., Dominey-Howes, D. \& Lloyd, K. (2010). Operational Challenges to Community Participation in Post-Disaster Damage Assessments: Observations from Fiji. Disasters, 34 (4), 1102-1122.

Ministerio de Ambiente, Vivienda y Desarrollo Territorial -MAVDT- (2011). Decreto número 1159 de 2011, por el cual se crea una Comisión Intersectorial para apoyar al municipio de Gramalote, departamento de Norte de Santander. Bogotá: MAVDT.

Municipio de Gramalote, Norte de Santander. (2002a). Documento Urbano. Gramalote: Esquema de Ordenamiento Territorial.

Municipio de Gramalote, Norte de Santander (2012). Compromiso con visión de cambio. Reescribiendo la historia de un pueblo, con la esencia del ayer, la transformación del hoy y la visión de un mejor mañana. Gramalote: Plan de Desarrollo Municipal 2012 - 2015.

Oliver-Smith, A. (2001). Consideraciones teóricas y modelos del reasentamiento de comunidades. En J.M. Macías. (Comp). Reubicaciones de comunidades humanas, entre la producción y reducción de desastres (pp. 61- 76). México: Universidad de Colima.

Orain, O. (2007, 19 de octubre). Constructivisme. Hypergéo. Recuperado de http://www. hypergeo.eu/spip.php?rubrique7

Quarantelli, E.L. (1998). What is a Disaster? London: Routledge. 
Scudder, T. \& Colson, E. (1982). From welfare to development: a conceptual framework for the analysis of dislocated people. En A. Hansen \& A. Oliver- Smith (Eds.). Involuntary Migration and Resettlement (pp. 267 - 287). Colorado: Westview Press.

Sánchez, J. A. (2011, 18 de junio). La persistencia de los gramaloteros. El Colombiano, Recuperado de: http://www.elcolombiano.com/BancoConocimiento/L/la_persistencia de_los_gramaloteros/la_persistencia_de_los_gramaloteros.asp: 